Research Article

\title{
A Prospective Observational Study on Anti-Infective Agents in Adults in A Hospital
}

\author{
Gada Yerukala Srawan Kumar*, Dr. Reddy Phani kumar ${ }^{1}$, Desireddy Rama Brahma Reddy², Yathirajam Dedeepya ${ }^{2}$, Naligala Divya ${ }^{2}$ \\ ${ }^{1}$ Physician St. Joseph General Hospital, Guntur, AP, India. \\ ${ }^{2}$ Nalanda Institute of Pharmaceutical Sciences, Kantepudi, Sattenapalli, Guntur, AP, India. \\ *Corresponding author's E-mail: gysrawan@gmail.com
}

Received: 11-03-2021; Revised: 24-05-2021; Accepted: 30-05-2021; Published on: 15-06-2021.

\section{ABSTRACT}

The main aim of the pharmacist is to provide the right drug in the right quality at the right time to patient. The monitoring studies of such prescription pattern can nourish the relevant use and exploit or misuse of the drug which is monitored. The main goal of the present study is to ease the rational use of drugs and make awareness of the irrational use of the drug which is more prevalent to the drug resistance, economic burden to the patient and failure of the treatment. The present prospective observational study was going on the usage of anti-infective agents in the adults based on the prescription of the physician to the patients. Prescriptions were obtained from various clinical departments was done over the period of 6 months from October 2020 to March 2021 to assess the appropriate use of anti-infective agents in adults. Total 1610 prescriptions data of anti-infective agents were analysed of average range of medication includes antibacterial, antiviral, antifungal, anthelmintic, antiparasitic, antimicrobials. A total of 1610 prescriptions from out patient and in patient department of the hospital were analysed in this study and out of those patients, male patients were 714 (44.34\%) and female patients were 896 (55.65\%). The most common age group which was prescribed more antiinfective agents was $51-60$ years. Among them the antibacterial were about $65.03 \%$, antiviral $1.59 \%$, antifungal $7.04 \%$, anthelmintic $7.09 \%$, antiparasitic $0.89 \%$, antimicrobial $0.51 \%$, antimalarial $0.93 \%$, antitubercular $0.51 \%$, Antibacterial+Antiprotozoal $16.45 \%$. Now a days usage of anti-infective agents was high to improve the rational use of drugs and to avoid the irrational usage of antibiotics in increasing the side effects and resistance towards the drug and total cost of treatment as well.

Keywords: Relevant, exploit, Prevalent, irrational use, awareness, Anti-infective agents.

QUICK RESPONSE CODE $\rightarrow$

DOI:

10.47583/ijpsrr.2021.v68i02.005

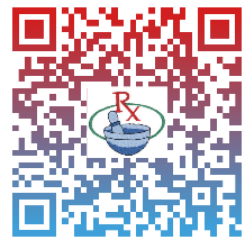

DOI link: $\underline{\text { http://dx.doi.org/10.47583/ijpsrr.2021.v68i02.005 }}$

\section{INTRODUCTION}

D rugs plays an important role to improve human health. ${ }^{1}$ Now a day's maximum we determined the infectious sicknesses that causes because of bacteria, virus, fungi and different parasites. These diseases were treated by anti-infective agents for specific diseases caused in patient. These infections are triggered because of incorrect sanitization, being contact with the triggering elements. Anti-infective agents which can be prescribed to forestall the increase of infectious agents which can be present inside the body. Infectious diseases means the contamination will develop in the body daily through micro-organisms.

Antivirals are the drugs which can be used to deal with the viral sicknesses besides HIV as it do now no longer have any precise treatment. ${ }^{2}$ The acute URTIs are in the mainly caused by the viruses in most cases and resolve spontaneously, hence antimicrobial agents don't seem to be necessary till its sophisticated and severe. The various studies found that antimicrobials were prescribed nearly $90 \%$ of pharyngitis. ${ }^{3}$

Most of the infectious diseases are due to fungi and the primary effected component in the fungal contamination is spores and skin. Skin is the most important element in our body and it is the most sensitive and cover everywhere in the body, subsequently it being contact with outside elements they will result in spores and skin diseases. ${ }^{4}$

Antiparasitic drugs are used to deal with the precise microorganisms that cause contamination because of the consumption of unhealthy food..$^{5} \mathrm{WHO}$ interpret Drug use evaluation (DUE) is an advancing, structured, criteria based program of medicine evaluations that will assist to sew up the precise medicinal drug use. ${ }^{6}$ This is very important in developing countries like India, where infectives and infectious diseases are more common. ${ }^{7}$ The fundamental intension of the study is to equalize the drug utilisation process and to promote the rational drug use. ${ }^{8}$

\section{MATERIALS AND METHODS}

\section{Study Design}

It includes the patients, usage of Anti-infective agents in St. Joseph Hospital, Guntur to study the comparison of opposite genders, age and prescription pattern of antiinfective agents.

\section{Study Design: 6 Months}


Source of Data: St. Joseph Hospital, Guntur (Private Hospital)

\section{Methods of collection of data:}

By reviewing prescriptions

By reviewing case sheets

Study population: All outpatients and inpatients of various clinical departments of St. Joseph Hospital in Guntur.

Sample size: 1610 patients were analysed and studied.

\section{Inclusion Criteria:}

1. Prescriptions containing one or more Anti-infective Agents.

2. All adult age $>20$ years prescribed with different Antiinfective agents were included.

3. The data thus obtained was entered in the Microsoft Excel software, was expressed the percentage and Proportions.

\section{Exclusion Criteria:}

1. Pregnant and Lactating females.

2. Cancer Patients.

3. Adult patients of age $<20$ years, neonates, infants, children, improper details or incomplete detailed prescriptions.

\section{RESULTS AND DISCUSSION}

Out of 1610 prescriptions, the use of anti-infective agents data were depicted in Table 1 with monotherapy is $71.86 \%$, 2 drug therapy with $23.91 \%$ and $4.23 \%$ had more than two anti-infective agents these was related to the study of Sonali Rode et al. ${ }^{9}$ In their study out of 385 prescriptions, use of antimicrobial monotherapy with $39.47 \%$ and 2 drug therapies with $34.55 \%$ and more than two antimicrobials was $25.71 \%$. The difference in the study was due to the duration, no of prescriptions collected by them in the randomised retrospective study.

Table 1: Based on drugs prescribed

\begin{tabular}{|c|c|c|}
\hline Parameters & $\begin{array}{c}\text { No of Prescriptions } \\
(\mathbf{n = 1 6 1 0 )}\end{array}$ & $\begin{array}{c}\text { Percentage } \\
\text { (\%) }\end{array}$ \\
\hline One drug & 1157 & 71.86 \\
\hline Two drugs & 385 & 23.91 \\
\hline Three drugs & 58 & 3.60 \\
\hline Four drugs & 8 & 0.50 \\
\hline >Four drugs & 2 & 0.13 \\
\hline
\end{tabular}

In this study total no of 1610 prescriptions were analyzed. Among them we found about 714 males (44.34\%) and 896 females (55.65\%) which was depicted in figure 1 . In this study, we analysed that the usage of anti-infective agents was more in females when compared to the males Sunil S Gidamudi et.al ${ }^{10}$ found the same result in their study.
Some results found exactly the opposite results in Naik HG et al. ${ }^{11}$

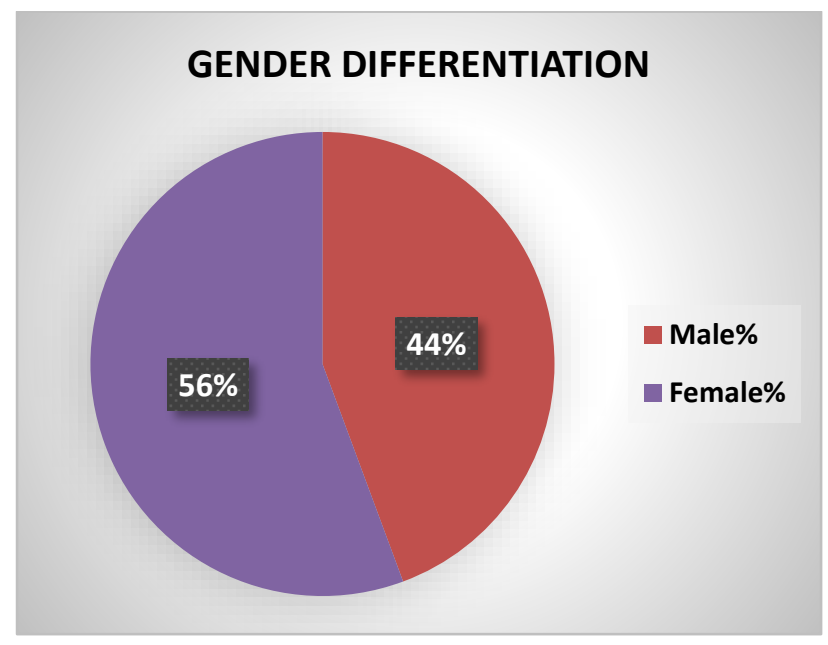

Figure 1: Gender differentiation in Prescriptions

In this study, a total of 1610 prescriptions were analyzed. A maximum number of patients belonged to the age group of 51-60 years data was depicted in the Figure 2 . The proportion of female patients was more compared to the male patients. The percentage of females were more compared to the male. Akram Ahmed et al., ${ }^{12}$ conducted a study shows that the maximum number of antimicrobials agents were prescribed to the age group between 30-60 years. This may be due to the fact that the elderly are more likely to get sick and have more serious illnesses than patients in other age groups.

Table 2: Patient Demographics

\begin{tabular}{|c|c|c|c|c|}
\hline Age & $\begin{array}{c}\text { Males } \\
(\mathbf{n = 7 1 4 )}\end{array}$ & $\begin{array}{c}\text { Males } \\
\mathbf{( \% )}\end{array}$ & $\begin{array}{c}\text { Females } \\
\mathbf{( n = 8 9 6 )}\end{array}$ & $\begin{array}{c}\text { Females } \\
\mathbf{( \% )}\end{array}$ \\
\hline $20-30$ & 104 & 6.46 & 199 & 12.36 \\
\hline $31-40$ & 127 & 7.89 & 154 & 9.57 \\
\hline $41-50$ & 147 & 9.13 & 225 & 13.98 \\
\hline $51-60$ & 181 & 11.24 & 193 & 11.99 \\
\hline $61-69$ & 155 & 9.62 & 125 & 7.76 \\
\hline
\end{tabular}

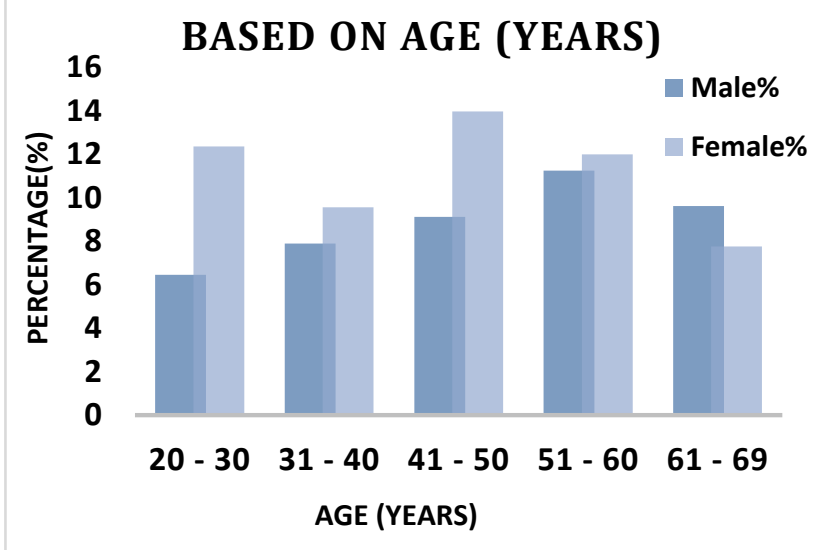

Figure 2: No of Prescriptions as per Patient Demographics 
In this study we observed that maximum drugs were use for treat of infective agents was antibacterial with $65.03 \%$ depicted in Figure 3 because of broad spectrum nature it is widely used in all type of diseases like UTI'S and URTI'S as we found the same results in Adugna Fenta et.al. ${ }^{13}$ followed by anthelmintic with $7.09 \%$ with minute difference of Antifungal with $7.04 \%$ and the least antiinfective agents were prescribed with Antimicrobials. Using broad spectrum agents, clear availability of antimicrobials in non-managed pharmacy, substandard/poor drug quality, pharmacological treatment termination and over-prescription because of a terrible diagnostic set-up or fear of loss of follow-up are among common elements improving antimicrobial resistance.

Table 3: Based on the category

\begin{tabular}{|l|c|c|}
\hline Category & $\begin{array}{c}\text { No of Drugs } \\
(\mathbf{n = 2 1 4 5 )}\end{array}$ & $\begin{array}{c}\text { Percentage } \\
\mathbf{( \% )}\end{array}$ \\
\hline Antibacterial & 1395 & 65.03 \\
\hline Antiviral & 34 & 1.59 \\
\hline Antifungal & 151 & 7.04 \\
\hline Antihelmentic & 152 & 7.09 \\
\hline Antiparasitic & 18 & 0.89 \\
\hline Antimicrobial & 11 & 0.51 \\
\hline Antimalarial & 20 & 0.93 \\
\hline Antitubercular & 11 & 0.51 \\
\hline Antibacterial+ & 353 & 16.45 \\
\hline Antiprotozoal & & \\
\hline
\end{tabular}

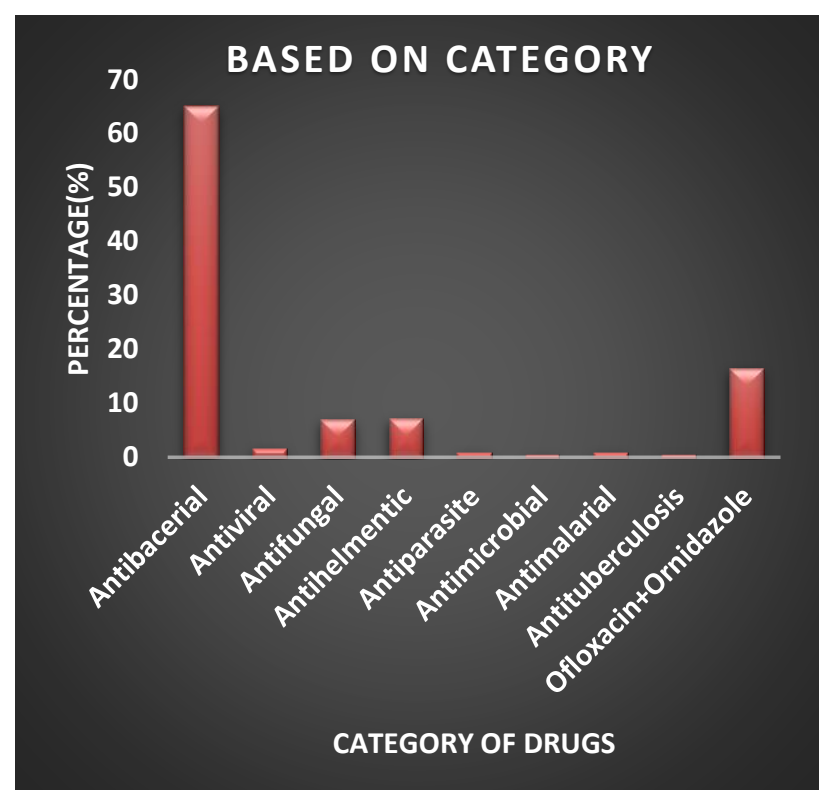

Figure 3: Percentage of anti-infective agents based on category

In the current study, most commonly used anti-infective agents were Amoxicillin+ clavulanic acid with 20.23\%, followed by the drugs with Ofloxacin+Ornidazole were prescribed with $16.45 \%$ and the least used Anti-infective agents are Povidone with $0.09 \%$ the data was depicted in Figure 5 showing the end result was compared with different research performed through Sanket b Sathiya et al., ${ }^{14}$ However of their study suggests that penicillin had maximum usually used followed by fluroquinolones. This difference is due to the condition based on the patient. A study by Inese Svi Estina et al., ${ }^{15}$ concluded that the most frequently used antibacterial agent between 2006-2015 and 2017 was Penicillin.

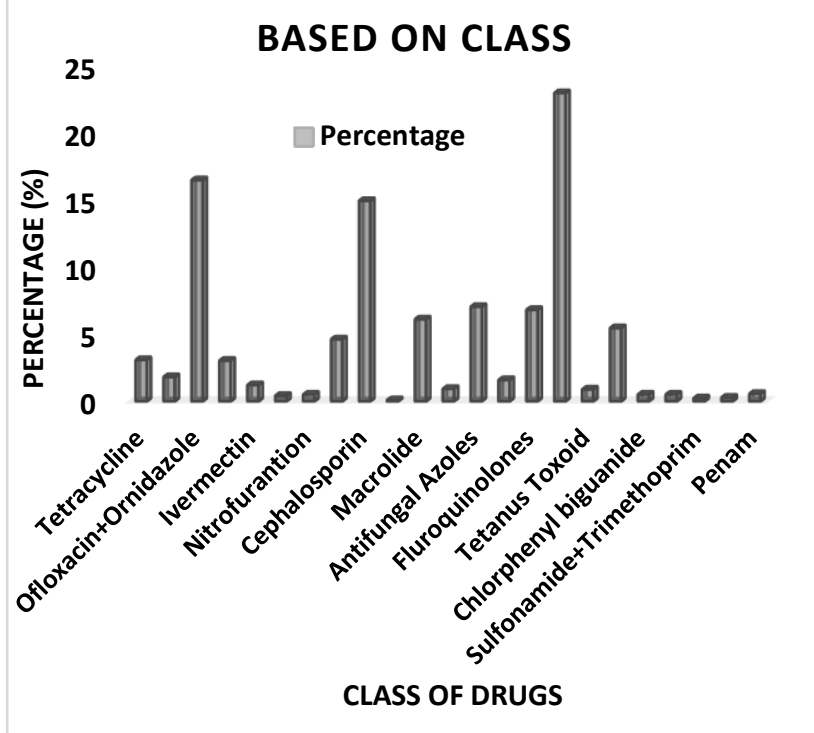

Figure 4: Prescribing frequency of anti-infective agents based on the class

Table 4: Based on the class

\begin{tabular}{|c|c|c|}
\hline Class of drugs & $\begin{array}{c}\text { No of } \\
\text { drugs } \\
(n=2145)\end{array}$ & $\begin{array}{c}\text { Percentage } \\
(\%)\end{array}$ \\
\hline Tetracycline & 66 & 3.08 \\
\hline Aminoglycoside & 39 & 1.81 \\
\hline Ofloxacin+Ornidazole & 353 & 16.46 \\
\hline Cefixime+Ofloxacin & 65 & 3.03 \\
\hline Ivermectin & 26 & 1.21 \\
\hline Diethylcarbamazine citrate & 9 & 0.42 \\
\hline Nitrofurantoin & 11 & 0.51 \\
\hline Nitroimidazole & 99 & 4.62 \\
\hline Cephalosporin & 320 & 14.92 \\
\hline Povidone & 2 & 0.09 \\
\hline Macrolide & 131 & 6.11 \\
\hline Artelone+Pipperaquine & 20 & 0.93 \\
\hline Antifungal Azoles & 151 & 7.04 \\
\hline $\begin{array}{l}\text { Synthetic nucleoside } \\
\text { analogues }\end{array}$ & 34 & 1.59 \\
\hline Fluroquinolones & 146 & 6.81 \\
\hline Penicillin & 492 & 22.94 \\
\hline Tetanus Toxoid & 19 & 0.89 \\
\hline Albendazole & 117 & 5.45 \\
\hline Chlorophenyl Biguanide & 11 & 0.51 \\
\hline Antimycobacterial & 11 & 0.51 \\
\hline Sulfonamide+Trimethoprim & 5 & 0.23 \\
\hline Scabicides+Pipperaquine & 6 & 0.28 \\
\hline Penam & 12 & 0.56 \\
\hline
\end{tabular}




\section{CONCLUSION}

From our study the usage of Anti-infective agents was more in females than males. Maximum number of patients were seen in age group between 51-60 due to immunity in old aged people was very low and can easily affected by infectious diseases. Antibacterial agents were most commonly used compared to the other anti-infective agents. According to our study, penicillin was most commonly used Anti-bacterial agent in 2020-2021.

Acknowledgement: We are very grateful to the patients who are participated in the study. Furthermore, we are especially thankful to the staff members at (St. Joseph General Hospital, Guntur, Andhra Pradesh). We thank HR manager, Manager of hospital ethics committee of St. Joseph Hospital. With all your support and help we successfully completed our project, we always faithful towards you.

\section{REFERENCES}

1. Sunilkumar. S, Nagajyothi. S, Dr. Sivaiah.K, Dr. Hindumathi. M, Dr. Madhusudana Chetty. C,Dr. Ugandhar. RE, A Prospective Observational study on Drug Utilization Pattern of Antibiotics During Pregnancy and Delivery in a tertiary Care Teaching Hospital, International Journal of Pharmaceutical Sciences Review and Research, 2020;6(1):227-232.

2. Srujana Gyawali, Nijan Upadhyay, Sabyata Gautam and Pradeep Paudel, A Study on drug use of ceftriaxone in a private hospital of Nepal, World journal of Pharmaceutical Sciences, 2015;3(1):111-119.

3. Nazz R, Chand S, Nandakumar U.P, Vinay B.C, Raj K.C.B, Shetty $S$, Prospective Observational Study on Prescribing Pattern of Antifungal Drugs in the 400 Out-Patient Department of Dermatology in Tertiary Care Hospital, Biomedical and Pharmacology Journal, 2021; 14(1):1-5.

4. Som J. Lakhani, Dhaval B. Joshi, Kalindi R. Kumbhani, Rajesh B. Haldia, Prospective study on comparison of efficacy of topical anti-fungal agents: clotrimazole $1 \%$ and sertaconazole $2 \%$ in treatment of tinea cruris, International Journal of Research in Dermatology, 2020; 6(1): 43-47.

5. Alarcon- Valdes P, Ortiz- Reynoso M, Santillan- Benitez J, Perspective on the Genetic Response to Antiparasitics : A Review Article, Iranian Journal of Parasitology, 2017; 12(4): 470-481.

6. Pramodh.B, M.Ashok Kumar, Dr.P.Shanmugasundaram, A Prospective Observational Study on Drug use Evaluation of Antiplatelet agents in Tertiary Care Hospital, Research
Journal of Pharmacy and Technology, 2017;10(12):43284332.

7. Anand Vardhan and C Dinesh M Naidu, A Study of the Prescribing Pattern of Antimicrobial Agents in a Tertiary Care Teaching Hospital of Andaman \& Nicobar Island, International Journal of Pharmacological Research, 2017; 7(4):94-97.

8. Admane PD, Hiware SK, Mahatme MS, Dudhgaonkar, Deshmukh SN and Mahajan MM, Prescription pattern of antimicrobials in tertiary care hospital in central India.International Journal of Pharmacological Research, 2015;5(2):31-34.

9. Rode $\mathrm{S}$ and Salankar $\mathrm{H}$, Analysis of antimicrobial usage pattern: a retrospective observational study, International Journal of Pharmaceutical Sciences Review and Research, 2018; 9(3): 1231-36.

10. Sunil S Gidamudi, Sujata A Jadhav, Chitra C Khanwelkar, Vandana M Thorat, Rohit R Desai, Harish G Naik, Drug Utilisation Study on Antimicrobial use in Urinary Tract Infection, International Journal of Medical Research, 2015; 5(3):216-221.

11. Naik HG, Khanwelkar CC, Kolur A, Desai R, Gidamudi S, Drug Utilisation Study on antibiotics use in lower respiratory tract infection, National Journal of Medical Research, 2018; 8(1): 34-39.

12. Akram Ahmad, Megha Revanker, Irfanul Haque, A. Pravina, Rahul Ivan, Ram Dasari, Sheetal Kuriakose, Isha Patel, Study the Prescription Pattern of antibiotics in the Medicine Department in a Teaching Hospital: A Descriptive Study, International Journal of Toxicological and Pharmacological Research, 2014;6 (2):43-46.

13. Fenta, A., Dagnew, M., Eshetie, S. et al. Bacterial profile, antibiotic susceptibility pattern and associated risk factore of urinary tract infection among clinically suspected children attending at Felege- Hiwot comprehensive and specialized hospital, Northwest Ethiopia. A prospective study, BMC Infectious Diseases,2020, 20:673.

14. Sanket B. Sathiya, Ashwin K. Panchasara, Manish J. Barvaliya, Sushil G. Jha, C.B. Tripathi, Drug utilisation pattern of antimicrobial agents in an outpatient department of otorhinolaryngology in a tertiary care hospital: a prospective, cross-sectional study, International Journal of Basic \& Clinical Pharmacology,2016;5(1):65-69.

15. Inese Sviestina, Dzintars Mozgis, Observational Study of Antibiotic Usage at the Children's Clinical University Hospital in Rigo, Latvia, Medicina, 2018; 54(5): 1-13.

Source of Support: The author(s) received no financial support for the research, authorship, and/or publication of this article.

Conflict of Interest: The author(s) declared no potential conflicts of interest with respect to the research, authorship, and/or publication of this article.

For any question relates to this article, please reach us at: editor@globalresearchonline.net New manuscripts for publication can be submitted at: submit@globalresearchonline.net and submit_ijpsrr@rediffmail.com 